\title{
Community Waste Plastic Recycling System Through Plastic Injection Molding
}

\author{
Lih Zhang Koo ${ }^{1}$, Douglas Kum Tien Tong, ${ }^{1, *}$, and Matias Rinne ${ }^{2}$ \\ ${ }^{1}$ School of Computer Science and Engineering, Faculty of Innovation and Technology, Taylor's \\ University, 1, Jalan Taylors, 47500 Subang Jaya, Selangor, Malaysia \\ ${ }^{2}$ Taylor's Me.reka Makerspace, G-10, SYPOZ Mall, 1, Jalan Taylors, 42500 Subang Jaya, Selangor, \\ Malaysia
}

\begin{abstract}
High demand for plastic worldwide has resulted in increasing environmental pollution. To make the plastic manufacturing process more environmentally friendly, recycling of waste plastic must be considered. In view of this a social enterprise called Me.reka Makerspace aims to use waste plastic to produce recycled plastic products using injection molding. However, injection molding is a complex process. In the past Me.reka experienced numerous failures resulting in defective plastic products and cost wastage. To assist with Me.reka's objective, this study aimed to recommend a process capable of producing good quality recycled plastic products that meet dimensional accuracy and surface roughness requirements. Literature review done on plastic waste separation techniques, plastic properties testing for injection molding, and ventilation systems. Manual plastic sorting was found to be the best for Me.reka, where it can separate all 7 types of plastics collected by Me.reka with the highest accuracy and efficiency and the lowest cost. The melt flow rate of specific plastic type can determine its compatibility for use in the injection molding machine. Furthermore this study found that the best ventilation system for Me.reka Makerspace's plastic injection molding facility was the displacement ventilation. It is expected that with the installation of an efficient ventilation system, the hazardous gasses produced during the process will be efficiently expelled thus protecting the health of workers. With regards to injection molding, a mold design was made for a book cover mold by applying the applicable mold design principles. However, this mold was later sent for testing at another facility. A flowerpot mold that had arrived at Me.reka which required immediate testing was tested instead. Through testing, improvements were made to the mold and the molding process by finding out the optimum injection molding temperature for the waste plastic used and the mold sprue diameter required to produce a well formed molding.
\end{abstract}

\section{Introduction}

Plastics have large chain like molecules, they are a polymeric material which consists of various types of elements such as oxygen, hydrogen, chlorine, carbon, and sulfur. Plastics

\footnotetext{
* Corresponding author: douglaskumtien.tong@taylor.edu.my
} 
was invented in $19^{\text {th }}$ century and was recognized as a great technological breakthrough at the time. Plastics has found increasingly widespread use in the manufacture of various products such as in shipping container, toys, packaging, electrical appliances, piping and household appliances due to its low cost, durability and ease of manufacture [1].

Within half a century the world's annual consumption of plastic increased 20 times, at 5 million tons in the 1950 s to 100 million tons in 2004 [2]. However, the escalating growth of plastic consumption has resulted in significant increase in the pressure to recycle as the production of new plastics will contribute greatly to reduction of raw material, as well as pollution to the environment [3-4]. Most plastics are polymetric materials that is nonbiodegradable with no capability of being self-decomposed by bacteria and thus pose a growing threat to the environment. More problems arise with the disposal of plastic wastes since landfill is limited [5]. The incineration of plastic wastes is limited too because of the negative impact of gas and dioxins emitted during the incineration of plastic wastes. It causes acid rain that can destroy architecture, soils, vegetation, rivers and wildlife. Recycling of waste plastics will help mitigate these problems. Compared to producing new plastics, recycling of plastics consumes $70 \%$ less energy [6] and reduces environmental damage.

Manufacture of plastic products is done in several ways such as plastic extrusion and plastic compression molding. The most common plastic manufacturing process is injection molding. This method is responsible for the manufacture of more than one third of all plastic products [7]. The process of injection molding begins by placement of plastic granules at the hopper. Plastic granules are guided into the barrel, where the heating process occurs. The heating temperature of barrel will be equivalent to the melting point of specific plastic used. The runner system located at barrel will then guide the melted plastic into a mold at a constant flow rate. Melted plastic will flow to fill in the shape of the mold. After cooling the mold is opened and the product is ejected.

This project is a collaboration with Me.reka Makerspace to assist Me.reka to recommend a process that is capable of producing good quality recycled plastic products which meets dimensional accuracy and surface roughness requirements through injection molding.

\subsection{Plastic waste materials}

Manual sorting of plastic waste is a technique which is effective in situations where large amounts of plastic components are present, thus, being able to justify the effort and time, considering the poor working environment and its labor intensiveness [8]. Plastic can be sorted manually according to the trademark, appearance, color, and shape of the plastic that is characterized visually by the operators [9]. Since it involves human effort the possibility of human error is always present and cannot be overlooked, even though the identification codes on the plastic materials are present. On the other hand, manual sorting is a relatively cheap method.

Another sorting technique is air sorting. Air sorting technique involves shredding the of plastic materials, with each shredded flake sized from 0.25 inch to $0.5 \mathrm{inch}$. The flakes are then fed vertically into air. An air stream is from an air jet blows the shredded flakes, causing the particles which are lighter to be separated away based on their specific gravity [10]. The air stream velocity can be adjusted to control the pressure drop based on the shredded plastic materials. Air sorting is useful in separating materials such as HDPE, PET, and film plastic [11].

Electrostatic sorting separates plastic materials by taking advantage of the differences in electrostatic charges between the plastic materials. The plastic materials will be dropped into the gap of two oppositely charged electrodes set parallel to each other. The plastic materials are separated based on its triboelectric charge, being attracted to either positively 
or negatively charged electrode. However, falling plastic materials with a very low charge will encounter weaker force acting on them resulting in separation error. Therefore, a long enough separation area between the two oppositely charged electrodes is needed. Even though the plastic materials that will undergo electrostatic sorting have very similar density, such as PP and PE, or having contaminants on the surface, the separation of plastic materials will still be carried out successfully. The efficiency of triboelectric separation by falling is poor if the plastic materials have insulating materials thicker than $2 \mathrm{~mm}$. Therefore, for cases with thick insulating materials, a roll type triboelectric separation would be more compatible [12].

Mechanical sorting separates materials based on their differences in mechanical properties, particle shape, elasticity, centrifugal force, and specific gravity. This separation technique is widely used in industries such as mining. However, this sorting technology is not specifically focused plastic sorting and more development is still needed for this purpose. The separation is done using a spinning centrifuge shaped like a bowl which separates plastic materials based on their specific gravity [13].

Sink float sorting is also known as density sorting, where the sorting depends on different plastics density. Plastics are separated by being placed in a fluid. Plastic materials with higher density than the fluid will sink, while plastic materials with lower density than the fluid will float. For the plastic materials with high density, water is commonly used as separation fluid [8]. To separate two different type of plastics, the fluid must be selected or adjusted to ensure the density is in the intermediate level between density of the two plastics. Some fluids have low density differences with the plastic materials, however, the sinking or floating will happen rapidly due to low viscosity of fluid [14]. Sink float sorting will make dirt or labels fall off from the plastic during its wet grinding phase, which is an added advantage of this method. However, this sorting technique is slow, giving low purity products, and is difficult to control.

Shaping of plastics are mostly performed by melting processes such as injection molding and extrusion of melted plastic. Therefore, the compatible measurement and testing for a plastic material prior to use in an injection molding will be testing of melt flow properties. Various tests categorized as low and high shear rate tests can be used to measure melt flow properties. Low shear rate testing is most commonly used such as the melt flow index test or the melt flow rate test [15].

Melt flow index (MFI) is defined as the melted material's ability to flow in a fixed interval of time, before being used in machines such as injection molding. MFI testing will be limited by the flowability of tested materials [16]. The standard SI unit used for MFI is gram per ten minutes $(\mathrm{g} / 10 \mathrm{~min})$, at a fixed temperature of 230 degree Celsius. The MFI has been known to be a very effective melt flow indicator to determine polymer-based material properties.

The melt flow tester has a piston that moves in a hot barrel to push and extrude the plastic sample while the barrel is heated to melt the plastic. A weight is installed at the top of the piston and the specified load will push the piston resulting in the melted plastic being extruded out via the die hole. The flow resistance and viscosity of the melted plastics flowing at a specified shear stress and temperature can be determined. The plastics with high molecular weights will have higher flow viscosities and thus lower MFI values. Hence plastic materials with lower MFI values will be harder to process due to its higher viscosity and flow resistance [17].

\subsection{Mold design}

Rapid prototyping can be used to create the molds for injection molding which cannot be built with a single process [18]. Even if a mold has complex geometry, rapid prototyping 
can still provide compatible components for injection molding [19]. Rapid prototyping has several advantages. It is possible for multiple parts to be fabricated and become a single assembly, where designs failures and flaws are easily detected without going through any manufacturing processes, and the manufacturing of a model can consist of multiple materials. However, a rapid prototyping machine is very expensive, the smoothness of the model created by this technique will exhibit stair stepping textures, and large sized parts are not compatible [20].

Rapid prototyping uses 3D CAD data to build the prototype using a material additive process. Any CAD software with the ability to create a 3D model will first be converted to 3D CAD data and sent to rapid prototyping machine before manufacture. In other words, if a 3D model is drawn using CAD software, with the correct conversion to CNC data file, the rapid prototyping machine will be able to build any freedom solid.

Steel is usually used for molds due to its machinability, reliability, and mechanical properties. The surface finishing of a steel mold will also ensure that the molded plastic product will have good surface aesthetic.

The molds for injection molding require high strength materials such as stainless steel, pre-treated steel, and tempered steel. The choice of mold material depends very much on the plastic materials to be molded. Metallic and mineral fillers have capability to grind on the surfaces of mold and is very abrasive to the hard surfaces, therefore, steel with high wear resistant tend to be selected as the mold. High wear resistant steel mold will also be selected if injection molding is to process plastic products frequently. One of the high wear resistance steel is tempered steel, which is harden by undergoing heating and cooling processes. Some fillers however will produce corrosive gases, such as fluoride and vinylic polymers, therefore, stainless steel with chemical resistance will be selected. Pre-treated steel molds can ensure the aesthetic of the surface finish of plastic products and it is used when there is no frequent plastic manufacturing processes and corrosive gases of fillers are absent [19].

Aluminium is also commonly used as mold material for injection molding. While steel is better for heat sustainability, the price for steel is higher. Aluminum is also is lighter which makes moving of mold easier. This saves time in the mold making process. One of the major advantages of an aluminium mold is that of heat dissipation, where it can be heated and cooled quickly.

Aside from pure steel or aluminium, alloy material can also be used. Alloy is known to have high conductivity, resulting in high heat transfer rate where the heating or cooling temperature will be spread evenly through mold. However, even with the good thermal conductivity and material properties of alloys, further researches and analyze should be done for a suitable alloy mold design [19].

Mold design is important to ensure that injected molded plastic products are manufactured effectively, efficiently, aesthetically, and accurately [21]. Part shape has a direct impact on manufacturing time of a mold. For example, if there are a screw threads or undercuts in a mold design, a separate moving part will be required on the mold, leading to an increase mold manufacturing time. The inner shell of a mold or the shape of molding will impact on mold manufacturing time by its thickness, surface area and weight. If the thickness of mold is varying due to its shape, the cooling must be done carefully during mold making. Otherwise excessive shrinkage of varying thickness will cause depressions or sink marks on the mold surfaces. The degree and quality of molding in terms of surface finishing must be considered before mold making. Aesthetic qualities for surface finishing of molding can be improved and adjusted by adding chemicals, etching, embossing, and other finishes. Considerations on whether a label or insert is needed for the mold must also be included during mold designing. The point where melted plastic will be introduced into a 
mold has to be considered at designing stage. Failure to do so will result in a further manufacturing stage for removal of surface blemishes which will result in extra costs.

The removal of a plastic product from a mold must also be considered. For example, if the mold shape has undercuts or closures, the removal of the plastic product will fail as the overlaying parts will prevent the ejection of the plastic product. Although some plastic product might be flexible enough to squeeze through, or the overlaying parts might be too small to prevent ejection, but a better solution will be needed by implementing a pedestal into the mold design. After cooling, pedestal will then be removed so that the ejection of the plastic cup can be done without having the cup base stuck within the wall of mold [21].

Injection molding has the capability to mold complex geometries but there will be defects if mold design rules are not followed. Following are the design rules for a injection molding mold [22]. Thick sections of mold should be hollowed out. The thickness of the wall is to be maintained under $5 \mathrm{~mm}$ to prevent poor mechanical properties and poor efficiency of cycling time. Varying wall thickness is to be avoided to prevent warpage caused by the large differences of shrinkage. Besides, with varying wall thickness, abrupt changes will increase the stress concentration shortening mold lifetime. Gradual change with varying wall thickness should be added for safer stress concentration. Radii to be added for inside walls, with a minimum radii half of the wall thickness. For example, a wall with $10 \mathrm{~mm}$ thickness should have at least $5 \mathrm{~mm}$ inner radii added. For outside walls, the radii are to be triple that of the wall thickness. For example, a wall with $10 \mathrm{~mm}$ thickness should have at least $30 \mathrm{~mm}$ outer radius added. For the boss that allows flowing of melted plastic into the mold, this requires a radius to reduce stress concentrations with the radius being one quarter of the boss wall thickness that does not go below 0.015 inches. For a better removal of plastic product from mold, a drafted angle on the wall must be considered. At least 0.5 degree is to be used to draft walls, ribs, or bosses of a mold. The draft angle must be done carefully otherwise instead of better ejection, the plastic product risk being stuck with undercuts [23].

\subsection{Room ventilation system}

Ventilation is needed to eliminate heat, fumes or smell trapped inside a room by replacement of indoor air with new air from outside of the room. The ventilation system creates a vacuum sucking out the contaminated air inside room, thus allowing air from outside of the room to fill in the vacuum [24].

Mixing ventilation (MV) is a system of using fresh air to mix with the contaminated room air, thus increasing the concentration of fresh air inside a room while decreasing the concentration of contaminated air [25]. Mixing ventilation uses air jet to stream in fresh air with velocity higher than $2 \mathrm{~m} / \mathrm{s}$, normally located at the top part of the room.

Displacement ventilation (DV) is a system which is most commonly used. DV replaces contaminated air inside a room with fresh air from outside of the room [26]. Compared with the air velocity of MV $(2 \mathrm{~m} / \mathrm{s})$, DV has a lower air velocity recorded at $0.5 \mathrm{~m} / \mathrm{s}$. The fresh air in DV system enters the contaminated room normally from the bottom part of room, while contaminated air will flow out at the top of the room, creating vertical gradients of fresh air concentration, room air temperature and air velocity inside the room. DV has higher efficiency in air distribution, increasing the fresh air concentration inside the room. It also requires lower power supply to the fan as the air velocity is lower at $0.5 \mathrm{~m} / \mathrm{s}$. However, DV is less efficient in cooling the room [27].

Impinging jet (IJ) system uses a similar concept to MV, i.e. by streaming fresh air inside the room to increases the fresh air concentration. IJ supplies fresh air to the room by the streaming of air towards the floor. It is then spread on the floor and the thin jet will follow along the floor area. IJ has high efficiency in supplying cool air into a room [28]. 
To calculate the performance of air distribution system inside a room, the air distribution index (ADI) used. It is a measure of the effectiveness in contaminant removal inside the room. ADI is a well-developed measurement of air distribution system performance [29]. A higher value of ADI will indicate a higher efficiency of ventilation system in air distribution. Based on Figure 1, DV has the highest ADI with a value of 3.02 compared to others, i.e., IJ with 2.63 and MV with 1.57.

\begin{tabular}{ccccccccc}
\hline Ventilation System & $|S|$ & $\varepsilon_{t}$ & $N_{J C}$ & $\tau_{n}(\mathrm{hr})$ & $\bar{\tau}_{p}(\mathrm{hr})$ & $\varepsilon_{c}$ & $N_{\Delta Q}$ & $(A D I)_{i}$ \\
\hline DV & $|0.17|$ & 1.10 & 1.04 & 0.33 & 0.23 & 1.35 & 1.98 & 3.02 \\
U & $|0.34|$ & 1.08 & 0.95 & 0.33 & 0.25 & 1.28 & 1.68 & 2.63 \\
MV & $|0.49|$ & 0.97 & 0.81 & 0.33 & 0.40 & 0.93 & 0.76 & 1.57 \\
\hline
\end{tabular}

Fig. 1. ADI of DV, IJ and MV [30].

\section{Materials and methods}

\subsection{Materials}

The thermoplastic used in this study was the recycled plastic type 2, High-Density Polyethylene (HDPE). This material was collected from both the recycling bin located at a mall and through contribution made by a plastic manufacturing company.

\subsection{Plastic waste separation technique}

For the evaluation of best plastic separation technique for Me.reka, cost and efficiency will be prioritized while sorting accuracy, power usage and hazardous emissions from the sorting will be considered. The rating for each criterion will start from 1 to 5 , with 1 as the worst and 5 as the best. For example, a 1 rating for cost means that the method is very expensive which is not good, while 5 rating means that it is an inexpensive method.

\subsection{Plastic waste separation standard operating procedure (SOP)}

As Me.reka focuses on cost more than anything else, manual sorting fits Me.reka's requirement the best as this method mostly only require human labor costs. The manual sorting workstation set up is based on Me.reka makerspace lab. To increase efficiency of manual sorting, the collection bag should have a larger opening area and the opening area of collection bag should always be fixed with a metal ring so that the collection bag will not close automatically resulting in workers having to reopen it as this lowers efficiency. The manual sorting workstation has 7 collection bags collecting 7 different types of plastic. However, to increase efficiency the number of collection bags can be reduced. For example, Me.reka only uses plastic type 2 (HDPE) and plastic type 5 (PP) to perform injection molding machine, while the other types plastic collected will be mixed and shredded to squeeze into a plastic bottle, which is known as plastic brick. The workstation needs to place 3 collection bags only, one for plastic type 2 , one for plastic type 5 , and one for all other types of plastic.

In some cases where the plastic type labelling is missing from a plastic product, the plastic waste separation cannot be performed manually. Based on the decision matrix, the second-best plastic sorting method can be implemented into SOP also. Sink float sorting begins with placing plastic material into tap water, where plastic pieces that float and sink 
will undergo different testing method to identify their plastic properties. The plastic that floats will then place into alcohol and increase the liquid density slowly by adding saturated water. PP, LDPE, and HDPE will float differently according to different liquid density. As Me.reka only uses PP and HDPE plastic, the plastic pieces that sink are not needed. However, to further determine plastic type such as PET, PLA, PS, and PVC that might be used in the future, the plastic waste separation SOP has included a method to determine all 7 types of plastic. The operating guideline for sink float sorting is shown in Appendix A.

\subsection{Material for mold}

Based on literature review, the material for the mold will be compared among stainless steel, pretreated steel, tempered steel and aluminium. The decision matrix to determine the mold material for Me.reka will focus on cost and efficiency while surface finishing of the plastic product, lifetime of mold, and hazardous emission from the molding process will also be considered.

\subsection{Mold designing}

The new mold is to be built for a plastic book cover using injection molding. CAD files will be sent to a CNC machining company for mold making. The sprue that function as the pathway for melted plastic to flow into mold will not be included. The sprue will be replaced by welding of a thread bush on the mold's outer surface. The thread bush with outer thread is chosen due to its compatibility with Me.reka's injection molding machine's nozzle head as Me.reka uses a nozzle head with inner thread. The material chosen for mold will be aluminium because it is cheaper and takes shorter time to produce the mold. Figure 2 (a) shows the initial upper part of mold, while Figure 2 (b) shows the initial lower part of mold. Based on the research done on the considerations for mold design and Me.reka's requirements, the mold was modified as shown in Figure 3.

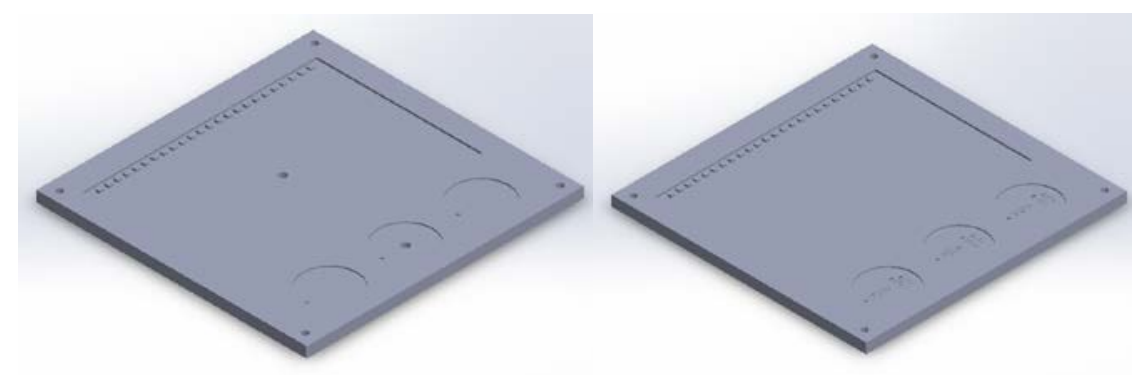

Fig. 2. (a) initial upper part of mold; (b) initial lower part of mold

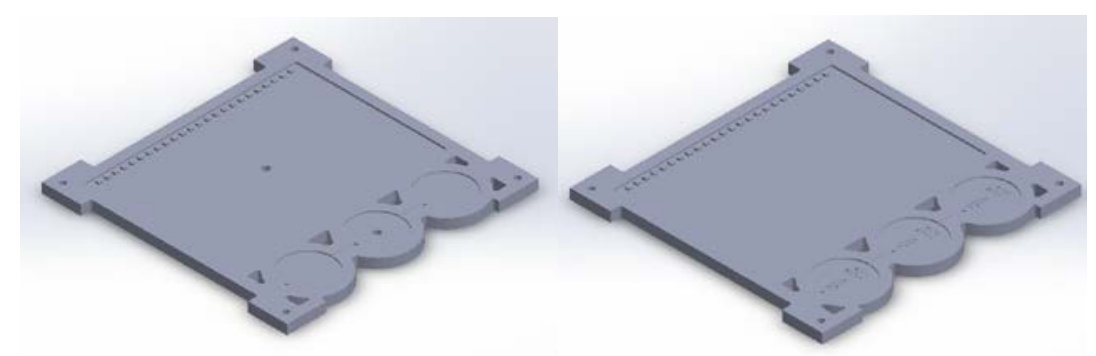

Fig. 3. (a) modified upper part of mold; (b) modified lower part of mold 
Referring to Figure 4, the mold body is hollowed out with cut extrude offset of $5 \mathrm{~mm}$. The reason of hollowing out this thick section is to prevent poor mechanical properties of the mold that will result in imbalanced cooling during injection molding. Imbalanced cooling will reduce the quality of surface finishing of the molded part. Although the mold performance might be better if the thickness is hollowed to below $5 \mathrm{~mm}$, however, imbalance cooling will occur in this case. Me.reka requires the mold thickness (inner body to outer body of mold) to be at a minimum of $5 \mathrm{~mm}$. To ensure balanced and smooth cooling of mold during injection molding, the hollowed parts thickness must be equivalent too. Another reason to hollow out only $5 \mathrm{~mm}$ is because of mold making cost. The thinner the hollowed shell body, the greater the part will cut by $\mathrm{CNC}$ machining, thus resulting in longer $\mathrm{CNC}$ machining time and higher cost.

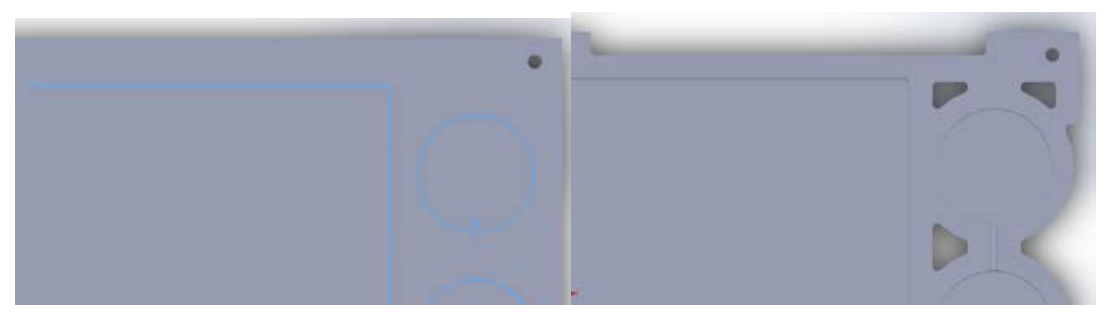

Fig. 4. (a) initial mold body; (b) hollowed mold body

As shown in Figure 5 the book cover structure and logo structure have varying thicknesses around them. The 90-degree edges will result in high stress concentration and therefore the lifetime of the mold will be shortened. $1 \mathrm{~mm}$ radii fillets are added to all the varying thickness points. The radii of fillets added is half of the varying thickness difference as recommended from mold design considerations researches.

As shown in Figure 6 the passage or runner structures are added in between the logo structures. Melted plastic will be injected into the logo structures through a sprue hole. The runner structure will allow the melted plastic from one logo structure to flow to another logo structure. The runner structure was modified with added fillets to reduce stress concentration.

Considering the mold making method is CNC machining which is unable to cut any sharp edges as the cutting tool of CNC is end mill, radii and fillets must be added to all sharp edges. As shown in Figure 7, the fillets chosen are set at radii of $1 \mathrm{~mm}$. Figure 7 (b) shows the edges that have been filleted for $\mathrm{CNC}$ machining.

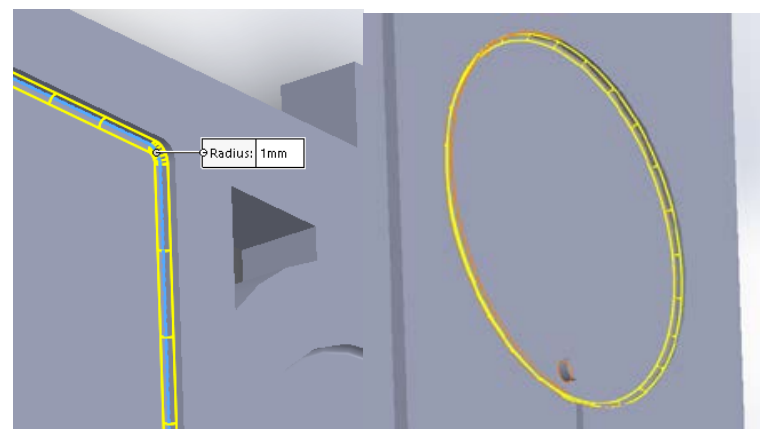

Fig. 5. (a) fillets at book cover structure; (b) fillets at logo structure 


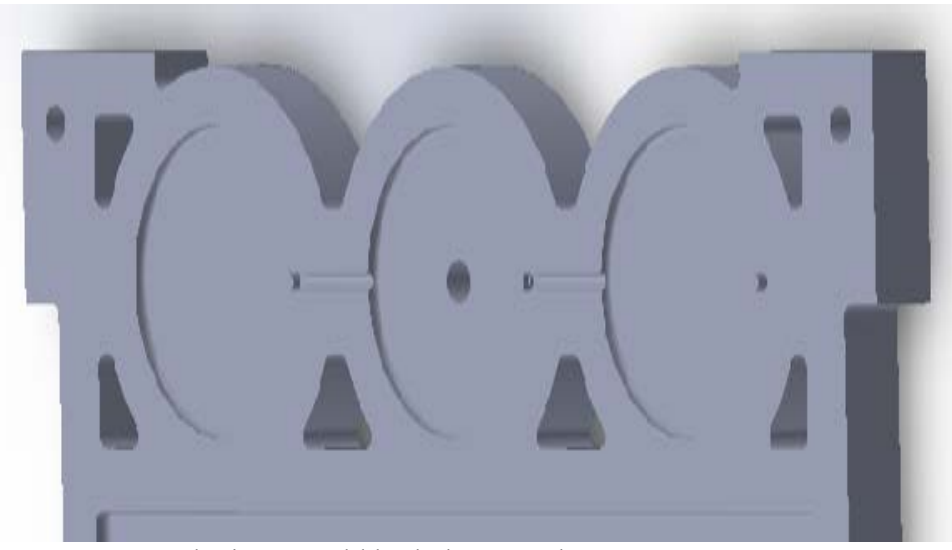

Fig. 6. Runner structures at the inner mold body between logo structures

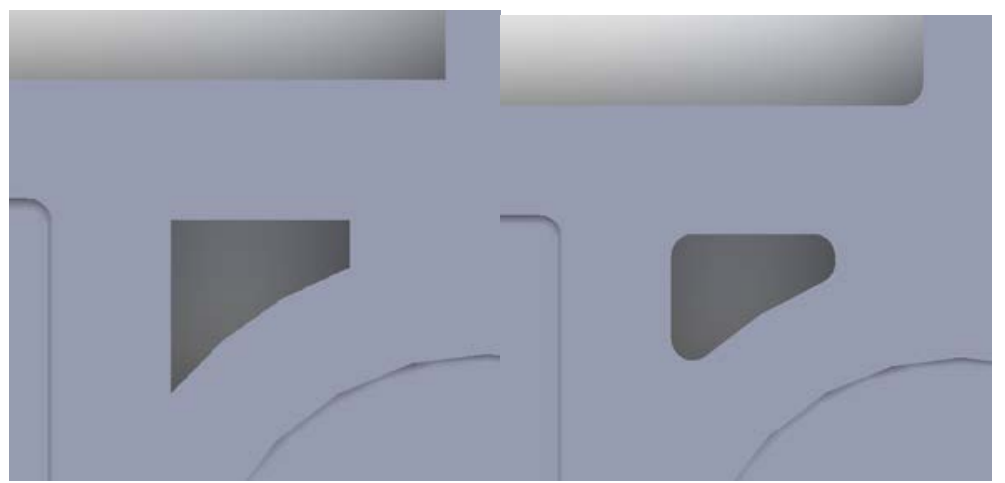

Fig. 7. (a) sharp edges at mold body; (b) filleted mold body

\subsection{Ventilation system}

For the evaluation of best ventilation system type that will fit Me.reka Makerspace's injection molding facility, a decision matrix was used. The main focus is the efficiency, followed by cost, environmental impact, space used and noise. 3 different type of ventilation system were evaluated, i.e. the mixing ventilation (MV), the displacement ventilation (DV) and the impinging jet (IJ).

\section{Results and Discussion}

\subsection{Decision matrix of plastic waste separation technique}

As shown in the decision matrix in Table 1, the best plastic waste separation technique for Me.reka is manual sorting. Manual sorting is low cost as it only requires human labor. Its efficiency is good as manual sorting is able to separate all types of plastic at once. The sorting accuracy is good but there will be some human error occurs as manual sorting is purely human labor. Human labor reduces power consumption and produces zero hazardous emission. For the other sorting techniques, electrostatic sorting and mechanical sorting requires expensive components to build hence their costs will be high. Air sorting uses components that are only slightly expensive. Sink float sorting requires chemical fluids and apparatus such as beakers. The sorting efficiency of air sorting, electrostatic sorting and 
sink float sorting are low because these processes can only separate 2 plastics at the same time, but there are more than 7 types of plastic collected by Me.reka. The sorting accuracy is very good in all sorting techniques. External power is needed in air sorting, electrostatic sorting, and mechanical sorting. However, no hazardous emissions happen from all sorting methods.

Table 1. Decision matrix of plastic sorting techniques for Me.reka

\begin{tabular}{|l|c|c|c|c|c|c|}
\hline Criterion & Weightage & $\begin{array}{c}\text { Manual } \\
\text { sorting }\end{array}$ & $\begin{array}{c}\text { Air } \\
\text { sorting }\end{array}$ & $\begin{array}{c}\text { Electrostatic } \\
\text { sorting }\end{array}$ & $\begin{array}{c}\text { Mechanical } \\
\text { sorting }\end{array}$ & $\begin{array}{c}\text { Sink float } \\
\text { sorting }\end{array}$ \\
\hline Cost & 5 & 5 & 3 & 2 & 2 & 3 \\
\hline Efficiency & 4 & 4 & 2 & 2 & 4 & 2 \\
\hline $\begin{array}{l}\text { Sorting } \\
\text { accuracy }\end{array}$ & 3 & 4 & 4 & 4 & 5 & 4 \\
\hline $\begin{array}{l}\text { Power } \\
\text { usage }\end{array}$ & 2 & 5 & 3 & 3 & 3 & 5 \\
\hline $\begin{array}{l}\text { Hazardous } \\
\text { emissions }\end{array}$ & 1 & 5 & 5 & 5 & 5 & 5 \\
\hline \multicolumn{2}{l}{ TOTAL SCORE } & 68 & 46 & 41 & 49 & 50 \\
\hline
\end{tabular}

\subsection{Decision matrix for mold material}

As shown in Table 2, the most suitable mold material for Me.reka is Aluminum. Aluminum is the cheapest material compared to the steel materials. The cost for mold making in terms of CNC machining lead time will also be lower as an aluminum mold requires shorter lead time to manufacture. However, $\mathrm{CNC}$ machining will be costly which is why aluminum is given a score of 4 . For the efficiency, aluminum score a maximum of 5 due to its shorter manufacturing time. Based on research, aluminum has great heat dissipation properties, as the time for the mold to heat up will be faster and after the melted plastic is injected, the cooling time is also fasterin addition, aluminum is lighter, which increases the workers' speed in handling the mold. For surface finishing of the product, aluminum mold would not be as good as that of pretreated steel but it still has similar surface finishing capability like the other steels. The lifetime of aluminium is shorter, which is why it only scores 2 . However, as there is no rapid injection molding activities in by Me.reka, the aluminum mold will still have a long life time. Any hazardous emissions from the aluminum mold will be mitigated by the ventilation system.

Table 2. Decision matrix for mold material

\begin{tabular}{|l|c|c|c|c|c|}
\hline Criterion & Weightage & $\begin{array}{c}\text { Stainless } \\
\text { Steel }\end{array}$ & $\begin{array}{c}\text { Pretreated } \\
\text { Steel }\end{array}$ & $\begin{array}{c}\text { Tempered } \\
\text { Steel }\end{array}$ & Aluminum \\
\hline Cost & 5 & 2 & 2 & 2 & 4 \\
\hline Efficiency & 4 & 4 & 4 & 4 & 5 \\
\hline $\begin{array}{l}\text { Surface } \\
\text { finishing }\end{array}$ & 3 & 4 & 5 & 4 & 4 \\
\hline Lifetime & 2 & 4 & 4 & 5 & 2 \\
\hline $\begin{array}{l}\text { Hazardous } \\
\text { emission }\end{array}$ & 1 & 5 & 3 & 3 & 3 \\
\hline \multicolumn{2}{|l}{ TOTAL SCORE } & 51 & 52 & 51 & 59 \\
\hline
\end{tabular}




\subsection{Decision matrix for ventilation system}

As shown in Table 3, the best ventilation system for this purpose is displacement ventilation system. In this system an exhaust fan will create a vacuum at the top of the room causing contaminated air and heat inside room to eject out. The efficiency of displacement ventilation is the best from the research conducted. The cost among the 3 ventilation systems are similar however the displacement ventilation system scored higher because of its lower operating cost as a lower fan speed is required. All the ventilation system types do not have good environmentally friendly impact as the air containing hazardous plastic fumes will be ejected out of the room into the surroundings outside of the room. This issue can be solved by placing an air filter at the outlet of ventilation system. IJ scored lower due to the dust on the floor might be blown to everywhere, as the IJ system will stream air onto the floor directly. DV will occupy the most space with the exhaust hoses, but with quieter noise due to lower fan speed.

Table 3. Decision matrix for ventilation system

\begin{tabular}{|l|c|c|c|c|}
\hline Criterion & Weightage & MV & DV & IJ \\
\hline Efficiency & 5 & 3 & 5 & 4 \\
\hline Cost & 4 & 4 & 5 & 4 \\
\hline $\begin{array}{l}\text { Environmental } \\
\text { impact }\end{array}$ & 3 & 4 & 4 & 3 \\
\hline Space used & 2 & 5 & 3 & 5 \\
\hline Noise & 1 & 3 & 4 & 3 \\
\hline TOTAL SCORE & & 57 & 67 & 62 \\
\hline
\end{tabular}

\subsection{Injection molding machine}

Tests were conducted by injecting melted plastic into a steel mold. For the first few tries of this injection molding, the plastic product was found to be not ideally shaped. This indicated there is room for improvement. The causes of the failures and suggestions to overcome them are listed below.

1. Shredded plastic that is being dropped and heated at the heating barrel of injection molding did not melt completely, especially at the nozzle head of injection molding.

- Material used for the nozzle head should be more heat-retaining. A collar or sheet could also be added around nozzle head. The heat loss from the nozzle head caused it to cool down and solidified the melted plastic before it enters the mold.

- Heating devices could be added or placed near the nozzle head for uniform heating of melted plastic before it enters the mold.

2. Plastic product stuck at mold's sprue

- A draft angle is needed at sprue's inner wall diameter for better ejection of finished product from the mold.

3. Plastic product from injection molding manufacturing process is not ideally shaped 
- Defects found on surface of the plastic product, which were unfilled and dented spots, rough surfaces and bent body. Air bubbles trapped in the melted plastic during plastic injection process might lead to dented spots and rough surfaces. Failure at completely melting the plastic or if the injection pressure is not high enough might lead to air bubbles trapped inside the plastic. Air bubbles trapped will also lead to rough surfaces.

- A further observation was done on the plastic product by cutting a section of it. The plastic on the surfaces with direct contact with the mold wall was rough and dented. However, the plastic on the inside had smooth and ideal surfaces. In other words, the plastic on the inside had no air bubbles. The air bubbles were only found around the outer surfaces of the plastic. The root cause seemed to be that the material used for the mold was unable to produce a smooth finish. The injection pressure must be higher as well so that outer surfaces will be fully filled according to contour of the mold wall.

\subsection{Flowerpot mold temperature test}

A flowerpot mold was tested instead of the book cover mold as the book cover mold was sent to another facility while the flowerpot mold had already arrived at Me.reka and immediate testing on it was required. Me.reka wanted to build a flowerpot made up of recycled plastic through injection molding. The body of flowerpot mold was made of aluminum while the adapter which acted as the sprue for the mold was made of stainless steel. The flowerpot mold body consisted of 2 connected subsystems i.e. the inner shell and the outer shell. The gap between both shells allowed melted plastic to fill up forming a flowerpot molding. For the sprue, it was a reducer adapter where the outer thread will fit into the injection molding machine, while having the inner diameter reduced from initial $15 \mathrm{~mm}$ (same as the injection molding machine heating barrel) to $5 \mathrm{~mm}$. During the injection molding process the injected plastic failed to achieve the expected outcomes as it only built up to the base of flowerpot partially. Based on this failure the root cause was investigated.

It was found that the plastic was not completely melted during the injection molding, which led to solid plastic forming a blockage at the sprue hole. This prevented melted plastic from flow further filling up the mold.

To ensure the plastic is melted completely before being injected into the flowerpot mold, the temperature had to be set higher for heating the barrel of injection molding machine. Initially the heating barrel temperature was set at $270{ }^{\circ} \mathrm{C}$. From this temperature, $10^{\circ} \mathrm{C}$ was for each test starting at $280^{\circ} \mathrm{C}$ until successful molding. Throughout the testing process, it was found that more and more plastic was filling up into the flowerpot mold until a temperature of $340{ }^{\circ} \mathrm{C}$ at which the plastic can be seen to burnt due to overheating. Figure 8 shows the 3 injected plastic samples from 3 different injection molding temperature, from left to right, which is $270{ }^{\circ} \mathrm{C}, 330{ }^{\circ} \mathrm{C}$ and $340{ }^{\circ} \mathrm{C}$, respectively. Comparing the test samples, successfully injected plastic is more when heating barrel temperature is increased, however at $340{ }^{\circ} \mathrm{C}$, the plastic has become black in color and the successfully injected plastic is less compared to $330{ }^{\circ} \mathrm{C}$. However, the testing of injection molding by increasing the temperature did not show a promising result as the plastic still only build up to the flowerpot base partially. 


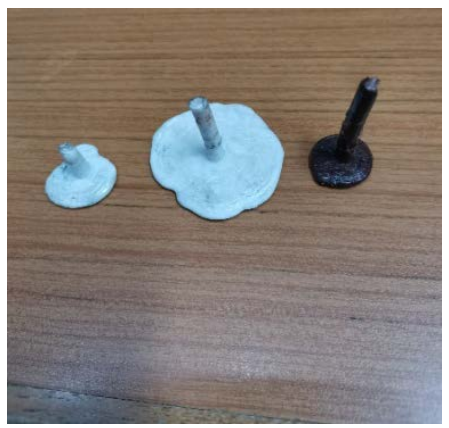

Fig. 8. Samples from $270{ }^{\circ} \mathrm{C}, 330^{\circ} \mathrm{C}$, and $340{ }^{\circ} \mathrm{C}$ testing

Based on Table 4, the result showed that when the temperature of the heating barrel increased, the area of successfully injected plastic increases However when the temperature was set at $340{ }^{\circ} \mathrm{C}$, the plastic started to burn and the area of successfully injected plastic decreased. The higher temperature will lead to melting more percentage of shredded plastic, thus leading to less solid plastic formed to block the sprue allowing more melted plastic to be injected into the mold. From this temperature test, the outcome was not achieved. Only the base part flowerpot was well formed. The testing did not manage to build up the flowerpot body. The conclusion drawn is that for Me.reka's injection molding the temperature is best set at $330{ }^{\circ} \mathrm{C}$ while the causes of the flowerpot mold failure can be attributed to factors beyond just temperature setting. Further investigation was conducted.

Table 4. Result of temperature testing using $5 \mathrm{~mm}$ sprue.

\begin{tabular}{|c|l|}
\hline Temperature $\left({ }^{\circ} \mathrm{C}\right)$ & Outcome description \\
\hline 270 & Less than $30 \%$ of flowerpot base is built up \\
\hline 280 & Less than $40 \%$ of flowerpot base is built up \\
\hline 290 & Less than $50 \%$ of flowerpot base is built up \\
\hline 300 & Less than $60 \%$ of flowerpot base is built up \\
\hline 310 & Less than $60 \%$ of flowerpot base is built up \\
\hline 320 & Less than $70 \%$ of flowerpot base is built up \\
\hline 330 & Less than $80 \%$ of flowerpot base is built up \\
\hline 340 & $\begin{array}{l}\text { Less than } 30 \% \text { of flowerpot base is built up, } \\
\text { plastic is burnt }\end{array}$ \\
\hline
\end{tabular}

\subsection{Flowerpot sprue diameter test}

The injection pressure required for the melted plastic to fill up the flowerpot mold was higher than maximum injection pressure the injection molding machine can exert. Thus, injection pressure was unable to reach the pressure for the melted plastic to completely fill the mold.

As shown in Figure 9, the flowerpot mold design experienced 2 pressure change stages i.e. from injection molding machine to the sprue $(15 \mathrm{~mm}$ to $5 \mathrm{~mm})$ and from sprue to the flowerpot mold body $(5 \mathrm{~mm}$ to $3 \mathrm{~mm})$. Based on Boyle's law, where volume $=(1 /$ pressure $)$, i.e. that when volume decreases, the pressure increases. From Figure 9, it can also observe that the plastic will be injected onto the surface of inner body directly before spreading to the side to fill up the mold, forming a direct backpressure. This will lead to greater injection pressure required for plastic to reach the $3 \mathrm{~mm}$ inner gap. 

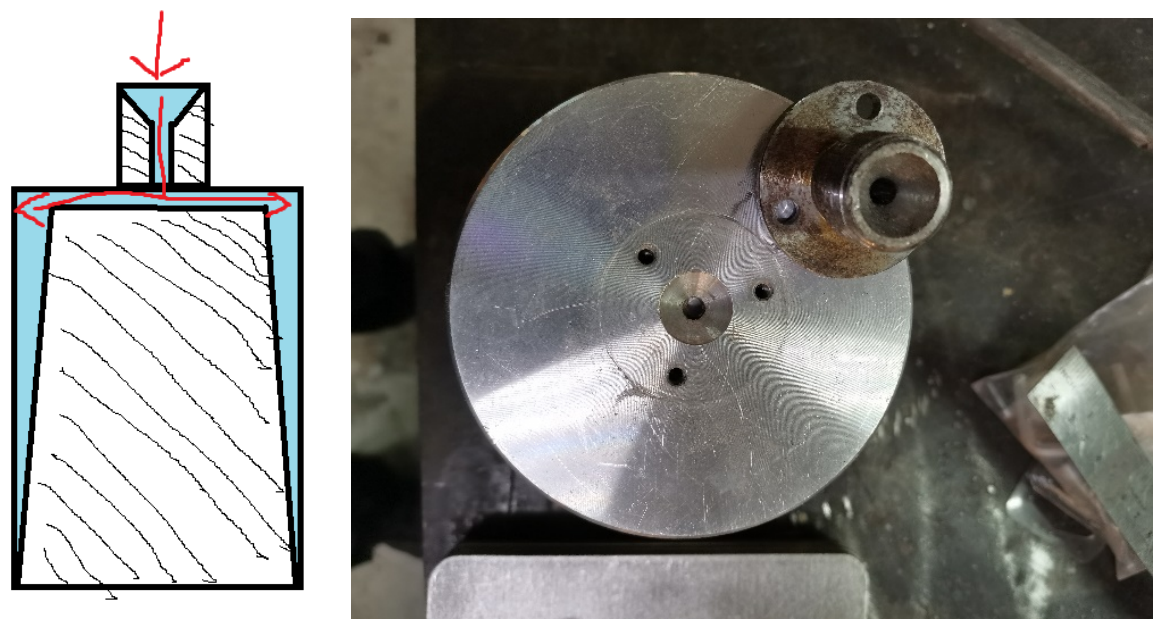

Fig. 9. Illustration of flowerpot mold pressure change spots

To overcome the insufficiency of injection molding pressure, there can be 2 solutions. The injection molding machine can be upgraded to one that can provide a greater injection pressure or the mold design can be modified such that it will require less injection pressure to fill the mold. The second option was chosen because it was more cost effective. Referring to Table 5, the sprue initially had a $5 \mathrm{~mm}$ diameter which could only inject up to the flowerpot base partially. By changing to a $10 \mathrm{~mm}$ sprue diameter, the injected plastic had successfully built up to half of the body of flowerpot mold but expected outcome was still not achieved. Since the pattern showed that increasing sprue diameter will result in larger volume of molding produced, the sprue diameter was then further increased to 13 $\mathrm{mm}$. With $13 \mathrm{~mm}$ sprue diameter, the flowerpot was completely filled as shown in Figure 10. Although the volume was achieved, however the surface smoothness still needed to be improved. The maximum allowable sprue diameter is $13 \mathrm{~mm}$, as the sprue of the flowerpot mold is $15.6 \mathrm{~mm}$ at outer diameter, which will leave very little thickness left if drilling of diameter above $13 \mathrm{~mm}$ is to be done. The sprue was made from stainless steel therefore it cannot be machined using the normal drill bits from Taylor University's manufacturing lab. Other methods had to be found to further improve the surface texture of end product. Cobalt drill bits have to be purchased for this purpose.

Table 5. Result of sprue diameter testing

\begin{tabular}{|c|l|}
\hline Sprue diameter $(\mathrm{mm})$ & Outcome description \\
\hline 5 & Less than $80 \%$ of flowerpot base is built up \\
\hline 10 & Less than $50 \%$ of flowerpot is built up \\
\hline 13 & Flowerpot product is built \\
\hline
\end{tabular}

The injection molding test was done using the modified flowerpot mold. The outcome was very promising although it did not successfully achieve its outcomes due to imperfections at the top part of the flowerpot. However, the injection molding under pressure for flowerpot mold was effectively understood. Figure 10 shows the outcome of modified flowerpot molding made with a sprue diameter of $13 \mathrm{~mm}$ and with an injection temperature of $330{ }^{\circ} \mathrm{C}$ versus the initial flowerpot molding. Notice the vast difference.

Increasing sprue diameters have resulted in superior end products as it requires less injection pressure to fill the mold. Further testing with larger sprue diameters up to a 
maximum of $15 \mathrm{~mm}$ can still be attempted on the current mold. However, this modification will require the use of cobalt drill bits to overcome machining challenges caused by the decreasing sprue wall thickness even as its diameter increases and the hardness of the stainless steel material.

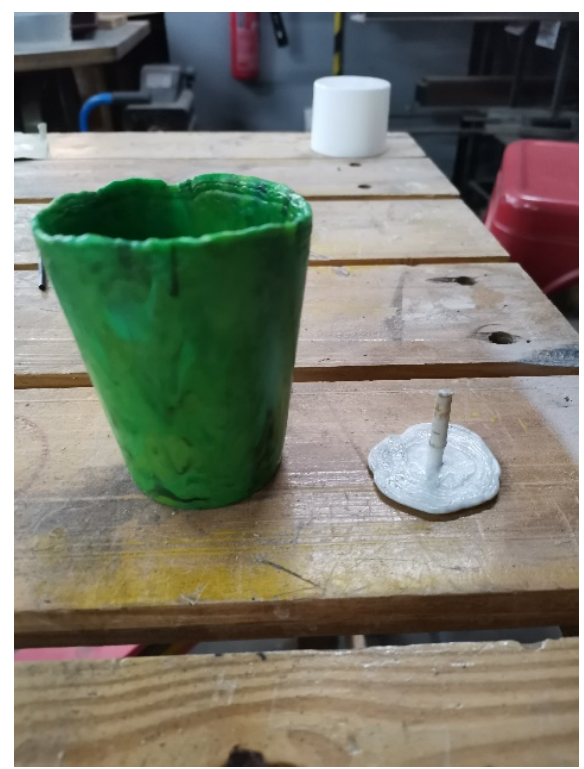

Fig. 10. Outcome after and before modification done on flowerpot mold

\section{Conclusion}

There had been studies done on injection molding using raw thermoplastics. However, only a few studies were done using recycled waste thermoplastics for injection molding. This research paper aims to contribute to the field of plastic waste recycling by encouraging the use of plastic waste injection molding. It was found that waste plastic can be injection molded into products such as flowerpots once the optimum molding temperature was found and a suitable sprue diameter used. Literature review on the most efficient and costeffective way to separate 7 type of plastic waste for recycling was also carried out. Based on a decision matrix, manual sorting was found to be the best method to sort waste plastic in terms of cost and efficiency. Literature review was also done to determine the plastic property that defines a thermoplastic type's compatibilty with the injection molding machine used. This property was found to be the melt flow index which can be tested using a melt flow tester. In addition, literature review showed that rapid prototyping of metal molds can be used for injection molding molds. The material used for a mold can be stainless steel, pre-treated steel, tempered steel or aluminum. Steel has higher tensile strength and longer lifetime than aluminum. However, as Me.reka will not be performing any rapid injection molding hence the most suitable mold material would be aluminum. Aluminum molds have a shorter lifespans than steel molds but costs less. Finally, the best ventilation system type for use at Me.reka's injection molding facility was also identified using a decision matrix and was found to be the displacement ventilation system.

The authors would like to thank Taylor's lab assistant Mr. Zulhairy Bin Haji Sahari and Me.reka's technician Mr. Taufiq for the help and support provided. 


\section{References}

1. I. Fortelný, D. Michálková, Z. Kruliš, Polym. Degrad. Stab. 85, 975-979 (2004)

2. T. Takoungsakdakun, S. Pongstabodee, Sep. Purif. Technol., 54, 248-252 (2007)

3. R. M. C. Santana, G. Gondim, J. Appl. Polym. Sci., 112, 1454-1460, (2009)

4. R. Saidur, M. Hasanuzzaman, M. A. Sattar, H. H. Masjuki, M. Irfan Anjum, A. K. M. Mohiuddin, Int. J. Mech. Mater. Eng., 2, 84-92, (2007)

5. J. Aurrekoetxea, M. A. Sarrionandia, I. Urrutibeascoa, M. L. Maspoch, J. Mater. Sci., 36, 2607-2613, (2001)

6. P. Santos, S. H. Pezzin, J. Mater. Process. Technol., 143-144, 517-520 (2003)

7. C. Shen, L. Wang, W. Cao, L. Qian, Polym. - Plast. Technol. Eng., 46, 219-225, (2007)

8. M. M. Wienaah. "Sustainable Plastic Waste Management - a Case of Accra, Ghana". Internet : https://silo.tips/download/sustainable-plastic-waste-management-a-case-ofaccra-ghana-michael-mensah-wienaa (2007)

9. J. Hopewell, R. Dvorak, E. Kosior, Philos. Trans. R. Soc., 364, 2115-2126 (2009)

10. Delgado C., Stenmark A. "Setting-up of European Virtual Institute for Recycling 'Virtual European Recycling Centre'. GTC1-2001-43018. VERC Deliverable report”. Internet:

http://www.wastexchange.co.uk/documenti/H\%20_Medio_Ambiente_PROYECTOS_ Z5008_verc_clara_WP2_refpaper_Refpaper_plastic_v2.pdf (2005)

11. A. Sutar, H. Salunkhe, Int. J. Innov. Res. Creat. Technol., 1, 320-322 (2015).

12. A. Tilmatine, K. Medles, M. Younes, A. Bendaoud, L. Dascalescu, IEEE Trans. Ind. Appl., 46, 1564-1569 (2010)

13. D. Teichmann, S. Masood, P. Iovenitti, I. Sharski, E. Kosior. "Development of High Performance Sorting Process for Recycling of Plastics". Internet: file://C:/Users/104225/Downloads/PDF\%20(Published\%20version).pdf (2002)

14. B. L. Altland, D. Cox, R. M. Enick, E. J. Beckman, Resour. Conserv. Recycl., 15, $203-$ 217 (1995)

15. Dynisco. "Materials and their Flow Properties". Internet: https://www.dynisco.com/userfiles/files/Materials_and_Flow_Properties

16. N. Fourati, N. Blel, Y. Lattach, N. Ktari, C. Zerrouki, Reference module in materials science and materials engineering (Elsevier, 2016)

17. Tinius Olsen. "Measuring Mass Flow Rate (MFR) and Other Polymer Properties". Internet: https://www.azom.com/article.aspx?ArticleID=4146 (2008)

18. B. Sriharsha, P. S. Rao, International Journal of Technical Innovation in Modern Engineering \& Science (IJTIMES), 4, 568-572 (2018).

19. J. Vasco, C. Capela, P. Bartolo, D. Granja. "Material Selection for High Performance Molds".

Internet: https://www.researchgate.net/publication/321655356_MATERIAL_SELECTION_FO R_HIGH_PERFORMANCE_MOLDS (2007)

20. S. O. Onuh, Y. Y. Yusuf, J. Intell. Manuf., 10, 301-311 (1999)

21. A. Riley, Plastics manufacturing processes for packaging materials (Woodhead Publishing Limited, UK, 2012).

22. 3DHubs. "Injection molding: The definitive engineering guide". Internet: www.3dhubs.com/guides/injection-molding/

23. RTP Co., "Part Design Guidelines for Injection Molded Thermoplastics". Internet: https://www.rtpcompany.com/wp-content/uploads/RTP-Part-Design-Guidelines-forInjection-Molded-Thermoplastics 
24. G. Cao, H Awbi, R Yan, Y Fan, K Siren, R Kosonen, J Zhang., Build. Environ., 73, 171-186 (2014)

25. D. Müller, C. Kandzia, R. Kosonen, A. K. Melikov, P. Vilhelm Nielsen, Mixing Ventilation - Guide on Mixing Air Distribution Design REHVA Guidebook 19, (REHVA, 2013).

26. H. Skistad, E. Mundt, P. V. Nielsen, K. Hagström, J. Railio, Displacement ventilation in non-industrial premises REHVA Guidebook 1, (REHVA, 2004)

27. Y. Cho, H. B. Awbi, T. Karimipanah, Build. Environ., 43, 1091-1100 (2008)

28. G. J. Poitras, A. Babineau, G. Roy, L. E. Brizzi, Int. J. Therm. Sci., 114, 184-195 (2017)

29. T. Karimipanah, H. B. Awbi, B. Moshfegh, J. Human-Environment Syst., 11, 77-84 (2008)

30. H. B. Awbi, Energy Procedia, 112, 277-286 (2017) 